\author{
Klaudiusz Nadolny ${ }^{1,2}$, Stanisław Szczerbiński ${ }^{3}$, Jerzy Robert Ładny ${ }^{4}$, Robert Gil ${ }^{5}$, Jacek Kubica ${ }^{6}$ \\ ${ }^{1}$ Faculty of Medicine, University of Technology in Katowice, Katowice, Poland \\ ${ }^{2}$ Department of Emergency Medical Service, Strategic Planning University of Dabrowa Gornicza, Dabrowa Gornicza, Poland \\ ${ }^{3}$ Emergency Medical Center in Opole, Poland \\ ${ }^{4}$ Department of Emergency Medicine, Medical University of Bialystok, Poland \\ ${ }^{5}$ Department of Invasive Cardiology, Institute of Experimental and Clinical Medicine, Polish Academy of Science, Warsaw, Poland \\ ${ }^{6}$ Collegium Medicum, Nicolaus Copernicus University, Bydgoszcz, Poland
}

\title{
Out-of-hospital cardiac arrest and COVID-19 pandemic
}

Key words: OHCA, COVID-19

The COVID-19 pandemic has caused profound changes in the functioning and effectiveness of healthcare worldwide. In particular, access to pre-hospital care has deteriorated, which was of particular importance for the effectiveness of treatment in patients with out-of-hospital cardiac arrest (OHCA). Regardless of this, infection with SARS-CoV-2 virus is a factor contributing to the occurrence of acute cardiovascular events, including OHCA.

Recently numerous reports regarding the impact of COVID-19 on the incidence of OHCA have been published. During the first wave of the COVID-19 pandemic in London, a dramatic rise in the incidence of OHCA, accompanied by a significant reduction in survival was observed. Moreover, the pattern of increased incidence and mortality closely reflected the rise in confirmed COVID-19 infections [1]. These observations were in line with the data collected from European, Australian, New Zealand and U.S. largest cities reviling showing significant OHCA escalations generally parallel to the local prevalence of COVID-19. Importantly, most of these patients died without COVID-19 testing [2]. Data from the North East England Ambulance Service revealed that despite reduced incidence of emergency calls during the pandemic compared with 2019, there was a rise in the incidence of OHCA and OHCA deaths during the same period [3]. Also, Glober et al. [4] observed increased OHCA incidence during the COVID-19 pandemic when compared with the prior year. Although patient characteristics were similar, initial shockable rhythm and proportion of patients who died in the hospital decreased during the pandemic. Rollman et al. [5] compared emergency medical services responses to out-of-hospital cardiac arrest (OHCA) and ST-segment-elevation myocardial infarction (STEMI) during the 2020 COVID-19 pandemic to 2018 to 2019 and evaluated the impact of California's March 19, 2020, stay-at-home order. Increase of weekly OHCA counts (173 vs. 135; incidence rate ratios, 1.28; $95 \% \mathrm{Cl}, 1.19-1.37 ; \mathrm{p}<0.001)$ and decrease of STEMI (57 vs. 65 ; incidence rate ratios, $0.87 ; 95 \% \mathrm{Cl}, 0.78-$ $0.97 ; p=0.02$ ) was found [5]. Wienbergen et al. [6] reported a significantly higher rate of patients admitted with cardiogenic shock ( $21.9 \%$ vs. $14.2 \%, \mathrm{p}<0.01)$ and out-of-hospital cardiac arrest (OHCA) (14.3\% vs. $11.1 \%$, $\mathrm{p}<0.01$ ) comparing the presentation of STEMI patients in the year 2020 with the years 2006 to 2019 in a German registry. In England, a significant increase in the incidence of OHCA in patients with acute myocardial infarction during the COVID-19 period paralleled with reduced access to guideline-recommended care and increased in-hospital mortality was observed [7]. The increased OHCA incidence and worse outcomes were also observed in Singapore and Poland during the COVID-19 pandemic [8, 9]. An increased in OHCA incidence by $62 \%$ during COVID-19 was observed in Detroit, without, however, a significant change in prehospital return of spontaneous circulation (ROSC) [10]. On the other hand, early during the pandemic, rates of sustained ROSC for OHCA were lower throughout the 
US, even in communities with low COVID-19 mortality rates [11]. Overall survival was also lower, primarily in communities with moderate or high COVID-19 mortality [11]. Contrary to most of the publications in the Netherlands during the first COVID-19 lockdown, the incidence of OHCA remained on the sable level, while there was a significant reduction in the number of patients with chest pain or STEMI [12]. A Spanish Nationwide Prospective Cohort Study showed that during the COVID-19 period, the incidence of resuscitation attempts declined and survival to hospital admission $(\mathrm{OR}=1.72 ; 95 \% \mathrm{Cl}=1.46-2.04 ; \mathrm{p}<0.001)$ and discharge $(\mathrm{OR}=1.38 ; 95 \% \mathrm{Cl}=1.07-1.78 ; \mathrm{p}=0.013)$ fell compared to the non-COVID period. This pattern was also observed when comparing non-pandemic weeks and pandemic weeks. COVID-19 incidence impinged significantly upon outcomes regardless of regional variation, with low, medium, and high incidence regions equally affected [13]. According to the report from the Swedish Registry for Cardiopulmonary Resuscitation during the pandemic phase, COVID-19 was involved in at least $10 \%$ of all OHCA cases. In this subset of patients, the 30-day mortality was 3.4-fold increased as compared to non-COVID patients [14]. Assessment of cardiopulmonary resuscitation practices during the COVID-19 period revealed a decrease in the initiation of these procedures regardless of whether patients were suspected of SARS-CoV-2 infection or not [15]. Therefore, it is extremely important to communicate good CPR practices to avoid a drastic and lasting reduction in survival after OHCA [15-17]. Two meta-analyzes agreed that the incidence and mortality following OHCA were higher during the COVID-19 pandemic $[18,19]$. Moreover, Borkowska et al. [19] showed that suspected or diagnosed COVID-19 resulted in a reduced survival rate after OHCA, probably due to the lower rate of shockable rhythms in COVID-19 patients, but not due to reluctance to bystander CPR.

COVID-19 has significantly impacted outcomes in OHCA patient through decreased access to medical care, and the reshaping of emergency medical response and hospital-based healthcare systems and policies. Moreover, changes in patient behaviour towards seeking help during the pandemic and the long-term consequences of not doing so should be taken into account [20-22]. Recently results of the OSCAR-POL registry have been published in Cardiology Journal [21]. This long-term observation from 2006 to 2018 showed circadian, monthly and seasonal variability of OHCA occurrence with no differences between particular days of the week. Significant circadian variability was observed within days of the week, seasons of the year, and particular years. Further in-depth studies on the impact of COVID-19 on the variability patterns of OHCA occurrence are necessary [23-26]. The research mainly based on registries should consider previously demonstrated risk factors and treatments [27-31]. This approach will allow to a full assessment of the impact of COVID-19 on OHCA.

\section{References}

1. Fothergill RT, Smith AL, Wrigley F, et al. Out-of-hospital cardiac arrest in London during the COVID-19 pandemic. Resusc Plus. 2021: 5: 100066 , doi: 10.1016/j.resplu.2020.100066, indexed in Pubmed: 33521706.

2. McVaney KE, Pepe PE, Maloney LM, et al. Writing group on behalf of the Metropolitan EMS Medical Directors Global Alliance. The relationship of large city out-of-hospital cardiac arrests and the prevalence of COVID-19. EClinicalMedicine. 2021; 34: 100815, doi: 10.1016/j. eclinm.2021.100815, indexed in Pubmed: 33997730

3. Charlton $\mathrm{K}$, Limmer M, Moore $\mathrm{H}$. Incidence of emergency calls and out-of-hospital cardiac arrest deaths during the COVID-19 pandemic: findings from a cross-sectional study in a UK ambulance service. Emerg Med J. 2021; 38(6): 446-449, doi: 10.1136/emermed-2020-210291, indexed in Pubmed: 33832923.

4. Glober NK, Supples M, Faris G, et al. Out-of-hospital cardiac arrest volumes and characteristics during the COVID-19 pandemic. Am J Emerg Med. 2021 [Epub ahead of print]; 48: 191-197, doi: 10.1016/j. ajem.2021.04.072, indexed in Pubmed: 33975130.

5. Rollman JE, Kloner RA, Bosson N, et al. Emergency medical services responses to out-of-hospital cardiac arrest and suspected ST-segment-elevation myocardial infarction during the COVID-19 pandemic in Los Angeles county. J Am Heart Assoc. 2021; 10(12): e019635, doi: 10.1161/JAHA.120.019635, indexed in Pubmed: 34058862

6. Wienbergen H, Retzlaff T, Schmucker J, et al. Impact of COVID-19 pandemic on presentation and outcome of consecutive patients admitted to hospital due to ST-elevation myocardial infarction. Am J Cardiol. 2021 [Epub ahead of print], doi: 10.1016/j.amjcard.2021.04.011, indexed in Pubmed: 34049671

7. Rashid Hons M, Gale Hons CP, Curzen Hons N, et al. Impact of coronavirus disease 2019 pandemic on the incidence and management of out-of-hospital cardiac arrest in patients presenting with acute myocardial infarction in England. J Am Heart Assoc. 2020; 9(22): e018379, doi: 10.1161/JAHA.120.018379, indexed in Pubmed: 33023348.

8. Lim SL, Shahidah N, Saffari SE, et al. Impact of COVID-19 on out-of-hospital cardiac arrest in Singapore. Int J Environ Res Public Health. 2021; 18(7), doi: 10.3390/ijerph18073646, indexed in Pubmed: 33807454.

9. Borkowska MJ, Smereka J, Safiejko K, et al. Out-of-hospital cardiac arrest treated by emergency medical service teams during COVID-19 pandemic: A retrospective cohort study. Cardiol J. 2021; 28(1): 15-22, doi: 10.5603/CJ.a2020.0135, indexed in Pubmed: 33140396

10. Mathew S, Harrison N, Chalek AD, et al. Effects of the COVID-19 pandemic on out-of-hospital cardiac arrest care in Detroit. Am J Emerg Med. 2021 [Epub ahead of print]; 46: 90-96, doi: 10.1016/j. ajem.2021.03.025, indexed in Pubmed: 33740572.

11. Chan PS, Girotra S, Tang Y, et al. Outcomes for out-of-hospital cardiac arrest in the United States during the Coronavirus disease 2019 pandemic. JAMA Cardiol. 2021; 6(3): 296-303, doi: 10.1001/jamacardio.2020.6210, indexed in Pubmed: 33188678.

12. de Koning ER, Boogers MJ, Bosch J, et al. Emergency medical services evaluations for chest pain during first COVID-19 lockdown in Hollands-Midden, the Netherlands. Neth Heart J. 2021; 29(4): 224-229, doi: 10.1007/s12471-021-01545-y, indexed in Pubmed: 33599968.

13. Rosell Ortiz F, Fernández Del Valle P, Knox EC, et al. OHSCAR investigators. Influence of the Covid-19 pandemic on out-of-hospital cardiac arrest. A Spanish nationwide prospective cohort study. Resuscitation. 2020; 157: 230-240, doi: 10.1016/j.resuscitation.2020.09.037, indexed in Pubmed: 33049385

14. Sultanian P, Lundgren $P$, Strömsöe A, et al. Cardiac arrest in COVID-19: characteristics and outcomes of in- and out-of-hospital cardiac arrest. A report from the Swedish Registry for Cardiopulmonary Resuscitation. Eur Heart J. 2021; 42(11): 1094-1106, doi: 10.1093/eurheartj/ehaa1067, indexed in Pubmed: 33543259.

15. Baert $\mathrm{V}$, Jaeger $D$, Hubert $H$, et al. GR-RéAC. Assessment of changes in cardiopulmonary resuscitation practices and outcomes on 1005 victims of out-of-hospital cardiac arrest during the COVID-19 outbreak: registry-based study. Scand J Trauma Resusc Emerg Med. 2020; 28(1): 119, doi: 10.1186/s13049-020-00813-x, indexed in Pubmed: 33339538. 
16. Kubica A. Rationale of cardiopulmonary resuscitation training as an element of multilevel educational and motivational project (MEDMOTION). Disaster and Emergency Medicine Journal. 2020; 5(2): 116-120, doi: 10.5603/demj.a2020.0017.

17. Sip M, Puslecki M, Dabrowski M, et al. Extended cardiopulmonary resuscitation: from high fidelity simulation scenario to the first clinical applications in Poznan out-of-hospital cardiac arrest program. Perfusion. 2020 [Epub ahead of print]: 267659120981811, doi: 10.1177/0267659120981811, indexed in Pubmed: 33325325.

18. Lim ZJ, Ponnapa Reddy M, Afroz A, et al. Incidence and outcome of out-of-hospital cardiac arrests in the COVID-19 era: A systematic review and meta-analysis. Resuscitation. 2020; 157: 248-258 doi: 10.1016/j.resuscitation.2020.10.025, indexed in Pubmed: 33137418.

19. Borkowska MJ, Jaguszewski MJ, Koda M, et al. Impact of Coronavirus disease 2019 on out-of-hospital cardiac arrest survival rate: A systematic review with meta-analysis. J Clin Med. 2021; 10(6), doi: 10.3390/jcm10061209, indexed in Pubmed: 33803944.

20. Kovach CP, Perman SM. Impact of the COVID-19 pandemic on cardiac arrest systems of care. Curr Opin Crit Care. 2021; 27(3): 239-245, doi: 10.1097/MCC.0000000000000817, indexed in Pubmed: 33783396.

21. Szczerbiński S, Ratajczak J, Jasiewicz M, et al. Observational analysis of out-of-hospital Cardiac Arrest occurRence and temporal variability patterns in subpopulation of southern POLand from 2006 to 2018: OSCAR-POL registry. Cardiology Journal. 2021, doi: 10.5603/cj.a2021.0060

22. Kołtowski $Ł$, Średniawa B, Tycińska $A$, et al. Predicting survival in out-of-hospital cardiac arrest patients undergoing targeted temperature management: The Polish Hypothermia Registry Risk Score. Cardiol J. 2021; 28(1): 95-100, doi: 10.5603/CJ.a2019.0035, indexed in Pubmed: 30994183.

23. Nadolny K, Bujak K, Kucap M, et al. The Silesian Registry of Out-of-Hospital Cardiac Arrest: Study design and results of a three-month pilot study. Cardiol J. 2020; 27(5): 566-574, doi: 10.5603/CJ.a2018.0140, indexed in Pubmed: 30444257.
24. Nadolny K, Zyśko D, Obremska M, et al. Analysis of out-of-hospita cardiac arrest in Poland in a 1-year period: data from the POL-OHCA registry. Kardiol Pol. 2020; 78(5): 404-411, doi: 10.33963/KP.15241, indexed in Pubmed: 32191020.

25. Szczerbiński S. Observational, retrospective analysis of the circadian variability of out-of-hospital cardiac arrest within days of the week. Medical Research Journal. 2020; 5(2): 68-71, doi: 10.5603/mrj. a2020.0020

26. Ratajczak J, Łach P, Umińska JM, et al. Mild therapeutic hypothermia after out-of-hospital cardiac arrest: What does really matter? Cardiol J. 2021; 28(2): 293-301, doi: 10.5603/CJ.a2019.0023, indexed in Pubmed: 30799547

27. Umińska JM, Ratajczak J, Buszko K, et al. Impact of mild therapeutic hypothermia on bioavailability of ticagrelor in patients with acute myocardial infarction after out-of-hospital cardiac arrest. Cardiol J. 2020; 27(6): 780-788, doi: 10.5603/CJ.a2019.0024, indexed in Pubmed: 30799546

28. Umińska JM, Buszko K, Ratajczak J, et al. Comparison of temperature measurements in esophagus and urinary bladder in comatose patients after cardiac arrest undergoing mild therapeutic hypothermia. Cardiol J. 2020; 27(6): 735-741, doi: 10.5603/CJ.a2018.0115, indexed in Pubmed: 30246234

29. Szczerbinski S, Ratajczak J, Lach P, et al. Epidemiology and chronobiology of out-of-hospital cardiac arrest in a subpopulation of southern Poland: A two-year observation. Cardiol J. 2020; 27(1): 16-24, doi: 10.5603/CJ.a2018.0025, indexed in Pubmed: 29611174.

30. Kubica J, Adamski P, Paciorek $\mathrm{P}$, et al. Anti-aggregation therapy in patients with acute coronary syndrome - recommendations for medical emergency teams. Experts' standpoint. Kardiol Pol. 2017; 75(4): 399-408, doi: 10.5603/KP.a2017.0057, indexed in Pubmed: 28421594.

31. Kubica J, Adamski P, Paciorek P, et al. Treatment of patients with acute coronary syndrome: Recommendations for medical emergency teams: Focus on antiplatelet therapies. Updated experts' standpoint. Cardio J. 2018; 25(3): 291-300, doi: 10.5603/CJ.a2018.0042, indexed in Pubmed: 29671864 